\title{
Protege Locus of Control and Psychosocial Mentoring: Mediating Role of Mentoring Initiation and Moderating Role of Trust
}

\author{
Muhammad Usman Anwar Baig* \\ Capital University of Science and Technology, Islamabad, Pakistan
}

\begin{abstract}
This study examined proteges work-locus of control, mediating role of mentoring initiation and moderating role of trust in mentor for successful psychosocial mentoring relationships at work. Data were collected using a self report questionnaire from a sample of 79 employees of a large commercial bank in Pakistan. Results of multiple regression analysis indicated that proteges external work-locus of control was negatively associated with psychosocial mentoring. However proteges mentoring initiation and trust on mentor did not play mediating and moderating role respectively in this relationship. The study discusses implications for theory and practice.
\end{abstract}

\section{Introduction}

Psychosocial mentoring was identified as a mentoring function in which mentors used counseling, acceptance and confirmation, and friendship to enhance proteges perceptions of competence, esteem and success at work (Kram, 1983). According O'Neill (2005), mentors provided counseling by discussing and advising on proteges personal and professional issues empathically, acceptance and confirmation by demonstrating respect for and trust in proteges personal and professional competencies, and friendship by informal interaction and voluntary discussion of topics both related or unrelated to work. According to Ghosh (2014), proteges high in proactivity, learning goal orientation, gender similarity with mentor, ethnic similarity with mentor, perceived similarity with mentor, age difference, cognition and affect based trust with mentor, informality of mentoring and perceived organizational support were more likely to receive psychosocial mentoring. Psychosocial mentoring had indirect rather than direct impact on proteges turnover intentions (Scandura and Schriesheim, 1994). Affective organizational commitment was found to mediate the relation of psychosocial mentoring and turnover intention (Craig et al., 2013). Organizational cooperative context and organic type were found positively related to psychosocial mentoring O'Neill (2005). Proteges reported more psychosocial mentoring from mentors internal rather than external to their organization (Baugh and Fagenson-Eland, 2005). Proteges in same race and same sex mentoring dyads reported receiving more psychosocial support than those in different race and different sex mentoring dyads (Thomas, 1990). No significant differ-

*Corresponding author.

Email: usman.a.baig@gmail.com ence was found in psychosocial mentoring provided by male and female mentors (Ensher and Murphy, 1997). Psychosocial support was found an important ingredient in expatriate success in international assignments (Shen and Kram, 2011). Proteges and their mentors perceive that mentors have a responsibility to provide psychosocial function however proteges receive less psychosocial function in formal mentoring relationship (Haggard and Turban, 2012). Psychosocial mentoring resulted into higher protege resilience against stress at work (Kao et al., 2014).

Meta-analysis of mentoring studies by Ghosh (2014) revealed heterogeneity of the effect size for the relationship between protg external locus of control and psychosocial mentoring thus implying possibility of presence of moderators such as relational factors (e.g. gender similarity, ethnic similarity, perceived similarity, self disclosure, self disclosure, age difference, and trust etc.) and or structural factors (e.g. mentoring type, supervisory status, perceived organizational support, and mentoring phase etc.). Thus there was a need to identify and examine factors at work that moderate the relationship between protg locus of control and psychosocial mentoring. There was also a need to confirm that mentoring initiation that mediated association of general locus of control and overall mentoring earlier (Turban and Dougherty, 1994) also mediated work specific locus of control and a sub function of mentoring called psychosocial mentoring in Pakistani context.

In this study, we shall examine impact of protgs work locus of control on psychosocial mentoring received with mediating effect of mentoring initiation and moderating effect of protgs trust on mentor. We are 
taking trust as a moderator because it has already been found to positively and significantly influence mentoring relationships (Chun et al., 2010; Richard et al., 2009) and therefore it is highly likely that it will moderate the relationship of locus of control and psychosocial mentoring function. We are taking mentoring initiation as mediator because it has been found to mediate general locus of control and mentoring relationship (Turban and Dougherty, 1994) and therefore likely to mediate between specific work locus of control and psychosocial function of mentoring. We are not aware of any study that examined moderating role of trust on mentor and mediating role of mentoring initiation over the relationship between protg external work locus of control and psychosocial mentoring.

This study adds to the literature of mentoring firstly by examining the direction of relationship between protgs external work locus of control and psychosocial mentoring i.e. positive or negative, secondly by examining the moderating effects of trust and thirdly by examining mediating effects of mentoring initiation on this relationship. It also instigates inquiry into exploring factors that moderate and mediate this developmental relationship. It also informs the practitioners about the fruitfulness of developing proactivity-enhancing and trust-enhancing interventions between mentoring dyads at workplace.

Two perspectives exist in mentoring research i.e. mentoring as received by protgs and mentoring as provided by mentors (Qian et al., 2014). This study follows the first perspective. Social exchange theory (Blau, 1964) and expectancy theory (Vroom, 1964) shall serve as the underpinning theoretical perspectives for this study in which social and psychological factors determine success of such developmental relationships. Mentoring is also an exchange relationship and thus makes it available for study under social exchange theory.

\section{Literature Review}

\subsection{Proteges work locus of control and psy- chosocial mentoring}

Proteges work locus of control (Spector, 1988) was defined as a personality trait characterized by the perception of the degree to which a protege could influence events and their outcomes at work. The construct of proteges locus of control was drawn from attribution theory (Heider, 1958). Later Rotter (1966) introduced differentiation of internal and external locus of control. However we shall be using context specific sub dimension of general locus of control i.e. work locus of control (Spector, 1988) which has been found to yield stronger relationship with work related criteria than general locus of control (Wang et al., 2010).
A protege with internal locus of control shall perceive that events and their outcomes are mostly under personal control. Whereas a protege with external locus of control shall perceive that events and their outcomes are mostly out of personal control i.e. under control of other influential persons, events or ultimately luck. Externals were more likely than internals to react with depression after a conflict (Hahn, 2000). Hence they are unlikely to initiate help seeking behavior even after facing personal and professional problems due to their beliefs of lower personal control. Proteges core self evaluation (a construct composed of locus of control, neuroticism, generalized self efficacy and self esteem) was found positively related to their report of mentoring received (Hu et al., 2014). Noe (1988) found that career planning and effective utilization of mentor (by discussing issues \& placing queries) led proteges to report receiving greater psychosocial mentoring than those who did not. Thus proteges with external locus of control are less likely to effectively utilize mentors due to their lack of personal control beliefs and thus likely to report lesser psychosocial mentoring.

H1. External locus of control at work will be negatively and significantly related with psychosocial mentoring.

\subsection{Mediating role of proteges mentoring initiation between work locus of con- trol and psychosocial mentoring}

Initiation of mentoring can be defined as a proactive behavior in which proteges take initiative to identify and engage a mentor to obtain career and psychosocial support (Turban and Dougherty, 1994). Kram (1983) described mentoring initiation as the first phase of mentoring relationship characterized by initiative taken by either or both protege and mentor. Our focus is proactive behavior of proteges for initiating mentoring and not the proactive behavior of mentors seeking proteges for mentoring provision.

Proactive personality was found positively related to psychosocial mentoring through voice behavior of proteges (Liang and Gong, 2013). Protege willingness to learn was positively related to mentors willingness to provide mentorship (Allen, 2004). One study found that mentors responded positively to their protege initiatives and encouraged their explorative behaviors (Janssen et al., 2013). Interaction opportunities influenced mentoring received through mediation of mentoring initiation by proteges (Aryee et al., 1999). Turban and Dougherty (1994) found that proteges can impact the mentoring received through their active engagement in initiation of mentoring behavior. They also found that the proteges with certain personality traits including internal locus of control were more likely to engage in initiation of mentoring behavior and in turn 
more likely to receive mentoring. This implies that proteges with external locus of control are less likely to engage in initiation of mentoring behavior. Their study did not distinguish between different mentoring functions received i.e. career, psychosocial and role modeling. Therefore we can deduce that proteges with external locus of control are less likely to engage in initiating psychosocial mentoring behavior and in turn or less likely to receive psychosocial mentoring.

H2. Mentoring initiation mediates the relationship of proteges external locus of control and psychosocial mentoring at work.

\subsection{Moderating role of trust between work locus of control and psychosocial men- toring}

Trust between protege and mentor can be defined as the degree of confidence in and intention to act upon on the statements, behaviors and decisions of each other (McAllister, 1995). The construct of trust between mentor and protege was derived from social exchange theory (Blau, 1964). It is also a source of successful social exchange relationships at (McAllister, 1995). There is evidence that trust can reduce opportunitism in social relationships (Williamson, 1979) thus it can lead to long term relationships. More trust was observed between same sex mentoring dyad than between cross sex mentoring dyad (Thomas, 1990). Lower traditionality (submission to authority) and higher trust of protege in mentor, when combined, strengthened the negative relationship of mentoring and job related stress (Qian et al., 2014).

The beliefs of proteges with external locus of control, that events and their outcomes are not under their control, are likely to prevent them from help seeking behaviors when facing personal and professional issues. Thus they are unlikely to share their emotions with and seek psychosocial support from others especially those whom they do not trust. Interpersonal comfort between mentor and protege plays an important role in successful mentoring relationship (Allen et al., 2005). Trust is likely to improve interpersonal comfort. Also proteges perceptions of lower control over events and their outcomes result into lower self esteem. Trust in formal mentor has been found to be positively related with proteges psychological meaningfulness, psychological availability and psychological safety of work (Li and Tan, 2013). Psychosocial mentoring is a mechanism to regain higher level of self esteem (Kram, 1983). Thus trust gives proteges the confidence to approach their mentor for receipt of psychosocial support. Proteges trust in mentor has been found to be positively related to mentoring in formal mentoring relationships (Chun et al., 2010; Richard et al.,
2009). Therefore it is likely that high trust in mentor shall weaken the negative relationship of proteges external locus of control and psychosocial mentoring at work. Moderately strong relationship was observed between trust and risk taking (Colquitt et al., 2007). Psychosocial mentoring involves risk taking on part of proteges due to disclosure of professional and personal problems of which mentors can take advantage if they want to. Thus we can propose proteges high in external locus of control are more likely to receive psychosocial mentoring in presence of trust than in its absence.

H3. Trust on mentor shall moderate the negative relationship between external locus of control at work and psychosocial mentoring in such a way that high trust on mentor shall weaken the relationship.

\section{Methodology}

\subsection{Population and Sample}

We collected primary data from employees working in a large commercial bank using a self report questionnaire. We contacted respondent personally at workplace and telephonically. Data were obtained off site. Personal and professional relations were used for identifying respondents and encouraging their participation. Respondents were requested to report information on all four variables in the questionnaire and return through expeditious means including courier service. The respondents were alerted to select responses based on their actual thinking and avoid wishful thinking. They were also guided to think about their relations with a mentor from whom they routinely take advice on their personal and professional issues. We confirmed the respondents complete anonymity of information. 200 questioners were distributed out of which 82 were received back and 79 were usable. Thus the response rate was $41 \%$. $67 \%$ of respondents were within age bracket of $26-33$ years. $52 \%$ of respondents were male and $48 \%$ were female. 67 percent of the respondents were Master degree holders. $83 \%$ of respondents were having experience less than 13 years.

We selected a banking organization for data collection because nature of work was relatively complex, stressful and working hours are long thus requiring junior employees to seek more mentoring from senior employees. Also education level and English language competency of bank employees was better than employees in other sectors that were helpful in accurate understanding of items. We explained purpose of our study and requested the bank to provide a list of employees. A list of 300 officers and executives of the bank was obtained. We used simple random sampling to identify 200 respondents. Data were collected during May and June 2015. Filled questionnaires were reviewed for completeness. 


\subsection{Measures}

This questionnaire included standardized instruments to measure protgs work locus of control, mentoring initiation, trust on mentor and psychosocial mentoring. Work locus of control described employees control beliefs over events and their outcomes at work (Spector, 1988). A 16 items instrument developed by Spector (1988) was used to measure protgs work locus of control. Sample items included: A job is what you make of it., If employees are unhappy with a decision made by their boss, they should do something about it., and Most people are capable of doing their jobs well if they make the effort. Cronbachs Alpha of these 16 items was 0.67. Mentoring initiation describes proactive behavior of protg to begin mentoring relation for career and psychosocial support (Turban and Dougherty, 1994). It was measured by using a four-item instrument developed by Turban and Dougherty (1994). Sample items included: sought to become acquainted (familiar) with higher-level managers., made personal efforts to have my work become visible to higher level managers., taken the initiative to seek counseling and advice from higher level managers., and taken the initiative to find mentors in the organization.. Permission for using the instrument was obtained from the developer. Cronbachs Alpha of these 4 items was 0.77 . Trust describes the level of confidence and intention to act upon on the statements, behaviors and decisions of each other (McAllister, 1995). Trust on mentor was measured by using 10 out of 11 items of an instrument developed by McAllister (1995) with sample items such as I can talk freely with mentor about difficulties I am having at work and know that (s)he will want to listen., We would both feel a sense of loss if one of us was transferred and we could no longer work together., and If I shared my problems with mentor, I know (s)he would respond constructively and caringly. Cronbachs Alpha of these 10 items was 0.81 . We dropped 1 item due to its lower relevance with protgs trust on mentor. The item, Given this persons track record, I see no reason to doubt his / her competence and preparation for the job is more relevant for measuring mentors trust on protg. Psychosocial mentoring describes a mentoring function in which mentors used counseling, acceptance and confirmation, and friendship to enhance protgs perceptions of competence, esteem and success at work (Kram, 1983). Noe (1988) developed a 29 item instrument for measuring mentoring that included items for measuring three functions i.e. career, psychosocial and role modeling. We adopted 11 items of this instrument measuring psychosocial function only with sample items such as My mentor has encouraged me to try new ways of behaving in my job., My mentor has demonstrated good listening skills in our conversations., and My mentor has shared personal experiences as an alternative perspective to my prob- lems.. Cronbachs Alpha of these 16 items was 0.90 . A five point Likert scale was used for all items with 1 representing Strongly Disagree and 5 representing Strongly Agree.

\section{Results}

\subsection{Correlation}

Statistical analysis including correlations and regressions were run on the data using SPSS. We controlled age, gender, qualification and experience.

Table 4.1 presents correlation among the model variables. Wok-locus of control was negatively, weakly and significantly associated with psychosocial mentoring $(r=-0.27, p \leq .05)$. It was negatively, moderately and insignificantly associated with mentoring initiation $(\mathrm{r}=-0.49, \mathrm{p}=.68)$. Mentoring initiation was positively, strongly and significantly associated with psychosocial mentoring $(\mathrm{r}=-0.50, \mathrm{p} \leq .01)$. Trust on mentor was positively, strongly and significantly associated with psychosocial mentoring $(\mathrm{r}=0.87, \mathrm{p} \leq .01)$. Worklocus of control was negatively, moderately and significantly associated with trust on mentor $(\mathrm{r}=-0.35, \mathrm{p} \leq$ .01 ). These bivariate associations lend tentative support for all hypotheses except for mediation due to insignificant association work-locus of control with mentoring initiation (the mediator).

\subsection{Regression Analysis}

Following are the results of regression analysis:

Hypothesis 1 predicted that external locus of control shall be negatively and significantly associated with psychosocial mentoring. We used regression analysis to test this hypothesis. In step 1, we introduced control variables in the model. In the second step, we regressed psychosocial mentoring on external locus of control. Table 4.2 shows results of regression analysis excluding t-test value and its $\mathrm{p}$-value. Value of slope coefficient $(\beta=-0.43)$ indicates that a unit change in locus of control shall yield a 0.43 units change in psychosocial mentoring in opposite direction. The coefficient of determination $R^{2}\left(R^{2}=0.12\right)$ indicates that control variables and locus of control when combined explain $12 \%$ of variation in psychosocial mentoring. Whereas change in coefficient of determination $\left(\Delta R^{2}\right.$ $=0.06$ ) indicates that locus of control alone accounts for $6 \%$ variation in psychosocial mentoring. And finally value of $t$ statistic above $2(t=-2.28)$ at significance level below $0.05(\mathrm{p}=.02)$ supports our hypothesis. Thus hypothesis 1 has been supported statistically.

Hypothesis 2 predicted that mentoring initiation shall mediate the association of external locus of control and psychosocial mentoring. Initially insignificant correlation was found between locus of control and psy- 
Table 4.1: Correlations and Reliabilities ${ }^{a}$

\begin{tabular}{lllll}
\hline Correlations & $\mathbf{1}$ & $\mathbf{2}$ & $\mathbf{3}$ & $\mathbf{4}$ \\
\hline 1. Work locus of control & $1(.67)$ & & & \\
2. Mentoring initiation & -0.05 & $1(.77)$ & & \\
3. Trust on mentor & $-.35^{* *}$ & $.47^{* *}$ & $1(.81)$ & \\
4. Psychosocial mentoring & $-.27^{*}$ & $.50^{* *}$ & $.87^{* *}$ & $1(.90)$ \\
\hline $\begin{array}{c}a \\
\text { tailed). }\end{array}$. & alpha reliabilities are mentioned in parentheses. & ${ }^{* *} p<.01$ (two tailed); ${ }^{*} p<.05$ (two
\end{tabular}

Table 4.2: Results of Regression Analysis for Outcomes

\begin{tabular}{|c|c|c|c|c|c|c|}
\hline \multirow[b]{2}{*}{ Predictor } & \multicolumn{3}{|c|}{ Mentoring initiation } & \multicolumn{3}{|c|}{ Psychosocial Mentoring } \\
\hline & $\beta$ & $R^{2}$ & $\Delta R^{2}$ & $\beta$ & $R^{2}$ & $\Delta R^{2}$ \\
\hline \multicolumn{7}{|l|}{ External locus of control } \\
\hline \multicolumn{7}{|l|}{ Step 1: } \\
\hline Control variables & & 0.01 & & & 0.06 & \\
\hline \multicolumn{7}{|l|}{ Step 2} \\
\hline External locus of control & -0.08 & 0.01 & 0.002 & $-0.43^{*}$ & $0.12^{*}$ & $0.06^{*}$ \\
\hline \multicolumn{7}{|l|}{ Mentoring initiation } \\
\hline \multicolumn{7}{|l|}{ Step 1: } \\
\hline Control variables & & & & & 0.06 & \\
\hline \multicolumn{7}{|l|}{ Step 2} \\
\hline Mentoring initiation & & & & $0.43^{*}$ & $0.30^{*}$ & $0.23^{*}$ \\
\hline
\end{tabular}

Table 4.3: Results of Mediated Regression Analysis for External locus of control

\begin{tabular}{lccc}
\hline \multicolumn{4}{c}{ Psychosocial Mentoring } \\
Predictor & $\beta$ & $R^{2}$ & $\Delta R^{2}$ \\
\hline External locus of control & & & \\
Step 1 & & & \\
Control variables & & & \\
Step 2 & & \\
Mentoring initiation & $0.43^{* * *}$ & $0.30^{* * *}$ & $0.25^{* * *}$ \\
Step 3 & & & \\
External locus of control & $-0.40^{* *}$ & $0.35^{* *}$ & $0.30^{* *}$ \\
\hline${ }^{* * *} p<0.001$ (two tailed); ${ }^{* *} p<.01$ (two tailed); ${ }^{*} p<.05$ (two tailed).
\end{tabular}

chosocial mentoring with $\mathrm{r}=-0.49$ and $\mathrm{p}=.66$. We further ran regression to test mediation and used the suggestions of a Baron and Kenny (1986). The first condition of this method required that significant association must hold between path (a) i.e. independent variable and proposed mediator. To test this first condition, we regressed mentoring initiation on external locus of control. In first step, we introduced control variables. In step 2, we regressed mentoring initiation on external locus of control. Results in Table 2 indicate that locus of control and mentoring initiation were negatively and insignificantly associated $(\beta=-0.08 ; \mathrm{p}=.71)$. The t-test value was also less than $2(t=-0.36)$. This means that first condition for mediation is not fulfilled and medi- 
ation does not exist statistically. Although it was not required to test other three conditions of mediation but we decided to check these conditions to reassure rejection of mediation hypothesis. Significant associations were observed between in path (b) i.e. mediator and dependent variable, path (c) i.e. between independent and dependent variable, and path (c) i.e. between independent and dependent variables after controlling mediator as indicated in Table 4.3, and hence mediation was absent statistically. Thus hypothesis 2 was not accepted statistically.

Hypothesis 3 predicted that trust on mentor shall play the role of moderator and shall reduce the negative association of external work locus of control and psychosocial mentoring. We used moderated regression analysis to test this hypothesis by determining interactive effects of proteges locus of control and trust on mentor on psychosocial mentoring. In first step, we introduced control variables to the model. In second step, we controlled both independent variable and moderator i.e. locus of control and trust on mentor. In the third step, we introduced the interaction term of locus of control trust on mentor and regressed psychosocial mentoring on this interaction term. Value of slope coefficient $(\beta=0.20)$ in Table 4.4 indicates that a unit change in interaction term (locus of control trust on mentor) shall yield a 0.20 units change in psychosocial mentoring in same direction. The coefficient of determination $R^{2}\left(R^{2}=0.79\right)$ indicates that control variables and interaction term (locus of control trust on mentor) when combined explain $79 \%$ of variation in psychosocial mentoring. Whereas change in coefficient of determination $\left(\Delta R^{2}=0.006\right)$ indicates that interaction term alone accounts for $0.6 \%$ variation in psychosocial mentoring. And finally value of $\mathrm{t}$ statistic below $2(\mathrm{t}=1.47)$ at significance level below $0.05(\mathrm{p}=.14)$ shows that interaction term is not significantly associated with psychosocial mentoring. Thus moderating effect of trust on association between locus of control and psychosocial mentoring is statistically insignificant and inconclusive. Thus our hypothesis 3 of moderation was not accepted statistically in this sample.

To summarize the results, our main hypothesis 1 is accepted due to statistical significance. However mediating hypothesis 2 and moderating hypothesis 3 , despite having strong theoretical support are not accepted due to statistical insignificance of results for current sample. At this point, one fact deserves attention i.e. introduction of moderator has changed direction (from negative to positive) and magnitude (from $\beta=-0.43$ to $\beta=0.20$ ) of our main hypothesis although at insignificant level $(p=.14)$. Thus trust on mentor has moderated the relationship in hypothesized direction but the effect is statistically insignificant and thus inconclusive.

\section{Discussion}

The objective of current study was examining the association between proteges external locus of control and psychosocial mentoring at work place with mediating role of proteges mentoring initiation and moderating role of trust on mentor. Our findings have led us to three main conclusions. First, we found a statistically significant negative association between external work locus of control and psychosocial mentoring. It was consistent with findings of Hu et al. (2014) in which they found positive relation between proteges core self evaluations and receipt of mentoring. Core self evaluation is a higher order construct that includes locus of control (Judge et al., 2003). Higher core self evaluations imply higher locus of control which is equivalent to lower external locus of control. Higher locus of control in core self evaluations is likely to yield higher receipt of mentoring ceteris paribus and similarly our lower external locus of control also leads to higher psychosocial mentoring which is a specific function of mentoring. Although apparently these two similar relations have opposite directions to each other but these have logically the same direction. It is likely that trait of high external locus of control reduces proteges' motivation to seek psychosocial mentoring support due to lower expectation of success in beginning and maintaining the mentoring relationship and of success of such relationship in resolving proteges psychosocial issues.

Second, we found that mentoring initiation did not act as a mediator between external locus of control and psychosocial mentoring. This was strange in view of previous findings of Turban and Dougherty (1994) in which mentoring initiation significantly mediated relationship between locus of control and mentoring. We could not establish statistical significance of relationship between external locus of control and mentoring initiation despite presence of strong theoretical support. The statistical insignificance of relationship might be explained by high uncertainty avoidance culture of respondents. Respondents of our sample belong to a national culture that is high on uncertainty avoidance (Hofstede and Hofstede, 1991). It is likely that respondents might be avoiding uncertainty stemming from exposure of their professional and personal problems to a potential mentor. This uncertainty might be leading to a fear of becoming victim of opportunistic behavior of potential mentor which might be preventing them from initiating psychosocial mentoring relationship.

Third, we found that trust moderated the association of locus of control and psychosocial mentoring in hypothesized direction but its impact was not statistically significant leading to rejection of our third hypothesis. The statistical insignificance of trust for relationship of locus of control and psychosocial mentoring might be explained by low individualistic culture 
Table 4.4: Results of Moderated Regression Analysis for External locus of control

\begin{tabular}{lccc}
\hline & \multicolumn{3}{c}{ Psychosocial Mentoring } \\
Predictor & $\beta$ & $R^{2}$ & $\Delta R^{2}$ \\
\hline External locus of control & & & \\
Step 1 & & & \\
Control variables & & 0.06 & \\
Step 2 & & & \\
External locus of control & 0.07 & 0.78 & $0.71^{* * *}$ \\
Trust on mentor & $1.07^{* * *}$ & & \\
Step 3 & & & \\
Locus of control Trust on mentor & 0.2 & 0.79 & 0.006 \\
\hline$* * * p<0.001$ (two tailed); ${ }^{* *} p<.01$ (two tailed); ${ }^{*} p<.05$ (two tailed).
\end{tabular}

of respondents i.e. trust is not relevant for respondents belonging to cultures of low individualism. Respondents of our sample come from a national culture that is low on individualism (Hofstede and Hofstede, 1991). This possible explanation is supported in literature in which high level of individualism was found to be negatively correlated with trust in peers (Kiffin-Petersen and Cordery, 2003). This finding underscores that trust gains more importance in individualistic cultures than in collectivist cultures. Thus trust might be an important moderator for relationship of locus of control and psychosocial mentoring between members of a highly individualistic culture but not for our respondents who come from a culture of low individualism.

\subsection{Theoretical and Practical Implications}

Our findings provide further support to existing literature of mentoring that proteges personality impacts mentoring relationships. Main theoretical contribution of our study is that important mediating and moderating mechanisms such as proteges mentoring initiation and trust on mentor respectively lose their relevance under certain conditions and thus become ineffective in explaining this vital relationship. This study opens inquiry into discovering conditions under which certain mediating and moderating factors are more relevant than others for this relationship. It also instigates search of more relevant mediating and moderating factors for this relationship. Several practical implications can be derived from our findings. Employees with external locus face difficulty in finding psychosocial support at work that has potential of hindering their effective functioning at work. Managers can provide psychosocial support to such employees to keep them working at optimal performance level. Organizations can provide formal and informal opportunities to resolve psychosocial issues of such employees. Such opportunities can include professional psy- chological help, indoor sports, and outdoor events for social interaction of junior and senior employees. Senior employees can be trained and encouraged to provide psychosocial support in form of counseling to employees facing psychosocial issues at work.

\subsection{Limitations and Recommendations}

Our study is not without certain limitations. First, a limitation was that all respondents came from same service setting i.e. banking. Their characteristics and work activities differ significantly from employees of other kinds of work setting e.g. production. Specifically their work was high in complexity, interdependence, and mental labor. They were more educated, recruited through more formal process, and used to receive formal functional trainings. Therefore the results of this study cannot be generalized to other work settings without caution.

Second, common method error was a concern as we collected data on all variables from only proteges through self report measures. However we believe that it is not a significant concern as all scales were measuring perception of proteges on items that were not judgmental of their performance and thus none of the scales appeared to motivate respondents to inflate their responses.

A third limitation was cross sectional design of the study. Longitudinal design could not be implemented due to limitation on resources of time, money and personnel for administering the study over multiple periods. Therefore results of this study should not be interpreted as causation.

Future researchers need to look for more relevant factors that could mediate and moderate this relationship in cultures that are different on cultural dimensions. Ghosh (2014) provides a useful list of factors that can be explored for potential mediation and moderation effects in this relationship. Greater sample size 
as well as diversified sample can be employed by including employees of other industries. Longitudinal study design contains good potential to infer causal relations. This relationship can be studied under different theoretical framework such as psychological contract breach.

This is the first empirical study to examine the mediation and moderation effects on relationship between external work locus of control and psychosocial mentoring from proteges perspective. Although no significant evidence of mediation and moderation was found in this study but these results are tentative and thus require further investigation with a larger and diverse sample. Also studies with mediators and moderators more relevant to this relationship and more relevant to a specific culture have potential of furthering mentoring theory and practice.

\section{References}

Allen, T. D. (2004). Protégé selection by mentors: Contributing individual and organizational factors. Journal of Vocational Behavior, 65(3):469-483.

Allen, T. D., Day, R., and Lentz, E. (2005). The role of interpersonal comfort in mentoring relationships. Journal of career Development, 31(3):155-169.

Aryee, S., Lo, S., and Kang, I.-L. (1999). Antecedents of early career stage mentoring among chinese employees. Journal of Organizational Behavior, pages 563-576.

Baron, R. M. and Kenny, D. A. (1986). The moderatormediator variable distinction in social psychological research: Conceptual, strategic, and statistical considerations. Journal of personality and social psychology, 51(6):1173.

Baugh, S. G. and Fagenson-Eland, E. A. (2005). Boundaryless mentoring: An exploratory study of the functions provided by internal versus external organizational mentors. Journal of Applied Social Psychology, 35(5):939-955.

Blau, P. (1964). Exchange and power in social life: Transaction publ.

Chun, J. U., Litzky, B. E., Sosik, J. J., Bechtold, D. C., and Godshalk, V. M. (2010). Emotional intelligence and trust in formal mentoring programs. Group $\mathcal{E}$ Organization Management, 35(4):421-455.

Colquitt, J. A., Scott, B. A., and LePine, J. A. (2007). Trust, trustworthiness, and trust propensity: a meta-analytic test of their unique relationships with risk taking and job performance. Journal of applied psychology, 92(4):909.

Craig, C. A., Allen, M. W., Reid, M. F., Riemenschneider, C. K., and Armstrong, D. J. (2013). The impact of career mentoring and psychosocial mentoring on affective organizational commitment, job involvement, and turnover intention. Administration E Society, 45(8):949-973.
Ensher, E. A. and Murphy, S. E. (1997). Effects of race, gender, perceived similarity, and contact on mentor relationships. Journal of Vocational Behavior, 50(3):460-481.

Ghosh, R. (2014). Antecedents of mentoring support: A metaanalysis of individual, relational, and structural or organizational factors. Journal of Vocational Behavior, 84(3):367384.

Haggard, D. L. and Turban, D. B. (2012). The mentoring relationship as a context for psychological contract development. Journal of Applied Social Psychology, 42(8):1904-1931.

Hahn, S. E. (2000). The effects of locus of control on daily exposure, coping and reactivity to work interpersonal stressors:: a diary study. Personality and Individual Differences, 29(4):729-748.

Heider, F. (1958). Consciousness, the perceptual world, and communications with others. Person perception and interpersonal behavior, pages 27-32.

Hofstede, G. and Hofstede, G. J. (1991). Cultures and organizations: Culture of the mind.

Hu, C., Baranik, L. E., and Wu, T.-Y. (2014). Antidotes to dissimilar mentor-protégé dyads. Journal of Vocational Behavior, 85(2):219-227.

Janssen, S., van Vuuren, M., and de Jong, M. D. (2013). Identifying support functions in developmental relationships: A self-determination perspective. Journal of vocational behavior, 82(1):20-29.

Judge, T. A., Erez, A., Bono, J. E., and Thoresen, C. J. (2003). The core self-evaluations scale: Development of a measure. Personnel psychology, 56(2):303-331.

Kao, K.-Y., Rogers, A., Spitzmueller, C., Lin, M.-T., and Lin, C.-H. (2014). Who should serve as my mentor? the effects of mentor's gender and supervisory status on resilience in mentoring relationships. Journal of Vocational Behavior, 85(2):191-203.

Kiffin-Petersen, S. and Cordery, J. (2003). Trust, individualism and job characteristics as predictors of employee preference for teamwork. International Journal of Human Resource Management, 14(1):93-116.

Kram, K. E. (1983). Phases of the mentor relationship. Academy of Management journal, 26(4):608-625.

Li, A. N. and Tan, H. H. (2013). What happens when you trust your supervisor? mediators of individual performance in trust relationships. Journal of Organizational Behavior, 34(3):407-425.

Liang, J. and Gong, Y. (2013). Capitalizing on proactivity for informal mentoring received during early career: The moderating role of core self-evaluations. Journal of Organizational Behavior, 34(8):1182-1201.

McAllister, D. J. (1995). Affect-and cognition-based trust as foundations for interpersonal cooperation in organizations. Academy of management journal, 38(1):24-59. 
Noe, R. A. (1988). An investigation of the determinants of successful assigned mentoring relationships. Personnel psychology, 41(3):457-479.

O'Neill, R. M. (2005). An examination of organizational predictors of mentoring functions. Journal of Managerial Issues, pages $439-460$.

Qian, J., Lin, X., Han, Z. R., Chen, Z. X., and Hays, J. M. (2014). What matters in the relationship between mentoring and job-related stress? the moderating effects of protégés traditionality and trust in mentor. Journal of Management $\mathcal{E}$ Organization, 20(5):608-623.

Richard, O. C., Ismail, K. M., Bhuian, S. N., and Taylor, E. C. (2009). Mentoring in supervisor-subordinate dyads: Antecedents, consequences, and test of a mediation model of mentorship. Journal of Business Research, 62(11):1110-1118.

Rotter, J. B. (1966). Generalized expectancies for internal versus external control of reinforcement. Psychological monographs: General and applied, 80(1):1.

Scandura, T. A. and Schriesheim, C. A. (1994). Leadermember exchange and supervisor career mentoring as complementary constructs in leadership research. Academy of management Journal, 37(6):1588-1602.
Shen, Y. and Kram, K. E. (2011). Expatriates' developmental networks: network diversity, base, and support functions. Career Development International, 16(6):528-552.

Spector, P. E. (1988). Development of the work locus of control scale. Journal of Occupational and Organizational Psychology, 61(4):335-340.

Thomas, D. A. (1990). The impact of race on managers' experiences of developmental relationships (mentoring and sponsorship): An intra-organizational study. Journal of Organizational Behavior, 11(6):479-492.

Turban, D. B. and Dougherty, T. W. (1994). Role of protégé personality in receipt of mentoring and career success. Academy of Management journal, 37(3):688-702.

Vroom, V. H. (1964). Work and motivation. new york: John willey \& sons. Inc. VroomWork and Motivation1964.

Wang, Q., Bowling, N. A., and Eschleman, K. J. (2010). A meta-analytic examination of work and general locus of control. Journal of Applied Psychology, 95(4):761.

Williamson, O. E. (1979). Transaction-cost economics: the governance of contractual relations. The journal of Law and Economics, 22(2):233-261. 